\title{
Observistotório
}

\section{COMUNICAÇÃO PÚBLICA E \\ CIDADANIA A PARTIR DAS \\ CONTRIBUIÇÕES DA \\ ECONOMIA POLÍTICA DA \\ COMUNICAÇÃO}

PUBLIC COMMUNICATION AND

CITIZENSHIP FROM THE

CONTRIBUTIONS OF POLITICAL

ECONOMY OF COMMUNICATION

COMUNICACIÓN PÚBLICA Y LA CIUDADANÍA DE LAS CONTRIBUCIONES DE ECONOMÍA POLÍTICA DE COMUNICACIÓN

\section{Mary Sandra Landim Pinheiro ${ }^{1}$ Jacqueline Lima Dourado ${ }^{2,3}$}

\section{RESUMO}

Este trabalho tem como objetivo trazer uma discussão teórica da Comunicação Pública e da Cidadania sob o viés da Economia Política da Comunicação, um campo que abrange questões relacionadas entre o mercado de comunicação, Estado e sociedade. A partir do conceito trabalhado por alguns estudiosos que ampliam as discussões sobre as temáticas é traçada uma definição de Comunicação Pública e Cidadania, posteriormente são elencadas pesquisas que aliam a lógica do público ao jornalismo diante de questões econômicas em

\footnotetext{
${ }^{1}$ Mestranda do Programa de Pós-Graduação em Comunicação da Universidade Federal do Piaú PPGCOM-UFPI,Membro do Grupo de Pesquisa em Comunicação, Economia Política e Diversidade (COMUM-UFPI). Bolsista Capes (Coordenação de Aperfeiçoamento de Pessoal de Nível Superior). Email: mary landim@yahoo.com.br.

2 Doutora em Ciências da Comunicação pela Universidade do Vale do Rio dos Sinos (UNISINOS), Professora do Programa de Pós-Graduação em Comunicação (PPGCOM/UFPI). Coordenadora do Grupo de Pesquisa em Comunicação, Economia Política e Diversidade (COMUM-UFPI). E-mail: jacdourado@uol.com.br.

${ }^{3}$ Endereço de contato dos autores (por correio): Universidade Federal do Piaú - UFPI. Programa de Pós-Graduação em Comunicação da Universidade Federal do Piauí Campus Universitário Ministro Petrônio Portella, Bairro Ininga, Teresina (PI), Brasil, CEP: 64049-550.
} 


\title{
Observistotório \\ ISSN n² 2447-4266 \\ Vol. 2, Especial 2, outubro. 2016 \\ DOI: http://dx.doi.org/10.20873/uft.2447-4266.2016v2Especial2p29
}

meio aos produtos que circulam no espaço televisivo, levando em consideração a comunicação pública como um mecanismo de resistência na esfera comunicacional.

PALAVRAS-CHAVE: Economia Política da Comunicação; Comunicação Pública; Cidadania.

\begin{abstract}
This work aims to bring a theoretical discussion of Public Communication and Citizenship under the bias of the Political Economy of Communication, a field that addresses issues between the communication market, state and society. From the concept worked by some scholars that expand discussions on the issues is drawn a definition of Public Communication and Citizenship, they are subsequently listed research that combine the logic of public journalism on economic issues among the products circulating in the television space taking into account public communication as a mechanism of resistance in the communication sphere.
\end{abstract}

KEYWORDS: Political Economy of Communication; Public communication; Citizenship.

\section{RESUMEN}

Este trabajo tiene como objetivo reunir una discusión teórica de Comunicación Pública y Ciudadanía bajo el sesgo de la Economía Política de la Comunicación, un campo que se ocupa de situaciones entre el mercado de la comunicación, el estado y la sociedad. Desde el concepto trabajado por algunos estudiosos que amplían las discusiones sobre los temas hasta la proyección de una definición de Comunicación Pública y Ciudadanía, que posteriormente se enumeraran en la investigación que combinan la lógica del periodismo público sobre temas económicos entre los productos que circulan en el espacio de la televisión teniendo en cuenta la comunicación pública como un mecanismo de resistencia en la esfera de comunicación .

PALABRAS CLAVE: Economía Política de la Comunicación; Comunicación Pública; Ciudadanía.

Recebido em: 30.12.2015. Aceito em: 19.08.2016. Publicado em: 30.10.2016. 


\section{Obevisto \\ ISSN n² 2447-4266 \\ Vol. 2, Especial 2, outubro. 2016 \\ DOI: http://dx.doi.org/10.20873/uft.2447-4266.2016v2Especial2p29}

\section{Introdução}

A proposta do artigo é fazer uma reflexão sobre o campo da Economia Política da Comunicação, levando em consideração algumas discussões traçadas nessa perspectiva teórica, a partir da reflexão estabelecida por meio de estudos desenvolvidos na área.

Para a organização do trabalho foi necessário traçar uma discussão sobre a Teoria da Economia Política da Comunicação. Para isso, são discutidas as contribuiç̧ões dadas pelas reflexões sobre as Indústrias Culturais Melo (2013), em seguida são expostas discussões sobre Economia Política da Comunicação Mosco (1999); Brittos e Dourado (2013), em seguida a contribuição sobre o Telejornalismo Público Becerra (2013), Valente (2009); Brittos e Dourado (2013).

Situando do ponto de vista teórico algumas reflexões importantes, para a configuração dos conteúdos divulgados por meio de mecanismos públicos, a citar a Televisão, como importante meio de difusão de informações, por estar presente nas casas da maioria da população brasileira, mas ainda com uma audiência maior voltada aos oligopólios comunicacionais. Também serão citados alguns pontos importantes para os conteúdos do telejornalismo público e também do papel do profissional, em meio ao cenário.

\section{Indústrias Culturais, breve contextualização}

O conceito de indústria cultural possui ao longo dos anos de utilização denominações e autores que trabalharam de forma distinta. De acordo com explanação de Melo (2013) desde o seu nascedouro onde o termo foi utilizado pela primeira vez na obra $A$ indústria cultural: o iluminismo como mistificação das 


\section{Observatório}

DOI: http://dx.doi.org/10.20873/uft.2447-4266.2016v2Especial2p29

massas, publicada em 1947. Nesse trabalho, estava relacionada principalmente à produção em ritmo industrial dado as obras de arte para Theodor Adorno e Max Horkheimer (1947), no qual a reprodutibilidade retirava a aura de originalidade. Em seguida, apresenta a visão de Walter Benjamim (1980), dando uma perspectiva mais positiva dentro da Escola de Frankfurt a reprodução, pois Benjamim acreditava que a reprodução expandia o acesso as obras de arte como uma garantia de democratização do conhecimento, antes oferecida apenas para poucos eleitos. O termo foi pluralizado por Bernard Miège, em 1978, no livro Capitalisme et Industries Culturelles, ofertando uma visão socioeconômica à difusão da arte, que passa a ser vista como negócio.

Dourado e Andrade (2013) contribuem com a discussão ao contextualizar o período histórico:

As diversas indústrias de produção simbólica (cinema, livro, música, TV, jornal, etc.) para tentar compreender o processo crescente de valorização das atividades culturais pelo capital, o que se verificou de forma ainda mais intensa a partir do final do século $X X$, período da reconfiguração capitalista de modo global. (DOURADO e ANDRADE, 2013, p. 298).

Sobre a temática, podemos acrescentar que "as indústrias culturais compõem um mercado produtor que, mais do que concorrencial, revela-se monopolista, controlado e produzido por poucas corporações" (DOURADO \& ANDRADE, 2013, p. 299). Os oligopólios centram o poder nas mãos de poucos, no caso brasileiro algumas famílias concentram o que é publico de forma privada, conforme apresenta Christofoletti (2003), onde 80\% de todos os veículos de comunicação do país estão concentrados nas mãos sete grupos. Apesar de passados doze anos, o poderio continua o mesmo, pois o controle se perpetua por gerações, enquanto o interesse e a rentabilidade ainda se mantêm ativos.

Cabe acrescentar, na atualidade o lugar ocupado pela televisão, onde ela é tida como um meio de destaque entre as indústrias culturais, nesse fim de século, conforme aponta Vizeu (2005) que é uma indústria cultural que tem uma 


\section{Observatório}

ISSN n² 2447-4266

Vol. 2, Especial 2, outubro. 2016

DOI: http://dx.doi.org/10.20873/uft.2447-4266.2016v2Especial2p29

participação decisiva na formação de identidades e no crescimento econômico dos países. Segundo o autor, o veículo tem baixo custo aos telespectadores, fator que o torna competitivo à publicidade e lembra o quanto para manter o funcionamento de uma emissora existem custos elevados de manutenção.

\section{Economia Política da Comunicação}

Ao refletir sobre a Economia Política da Comunicação (EPC), faz-se necessário ampliar a discussão da temática. Primeiramente, é preciso contextualizar a lógica de pesquisa que tem início nas discussões sobre economia política. Segundo Mosco (1999), possui duas definições centrais se coloca como o "estudo das relações sociais, em especial das relações de poder, que constituem a produção, distribuição e consumo de recursos, incluindo os recursos de comunicação" (MOSCO, 1999, p.98). Também acrescenta o objetivo do estudo nessa área da compreensão da mudança social e transformação histórica. Ainda de acordo com o autor, o faturamento publicitário obtido por meio da audiência é o que sustenta a produção do que é feito pelos meios de comunicação.

O referido campo de estudo tem um recurso didático proposto por Marques de Melo (2013), onde são apresentadas duas linhas de raciocínio: primeiramente, a pragmática, ligada às abordagens que preservam o sistema econômico hegemônico na sociedade, e a crítica que tem inspiração nas influências do marxismo e problematiza as estruturas vigentes.

Ao expor o campo de estudo da Economia Política da Comunicação, em obra que trata sobre abordagens a diversas Teorias da Comunicação, o pesquisador Adilson Vaz Filho, situa o campo como a "recomposição da participação dos setores sociais nos diversos processos de produção comunicacional, compreendendo a atual dinâmica de circulação de mercadorias e recomposição dos mercados na assim chamada sociedade da informação" (FILHO, 2014, p. 69). 


\section{Observatório}

ISSN n² 2447-4266

Vol. 2, Especial 2, outubro. 2016

DOI: http://dx.doi.org/10.20873/uft.2447-4266.2016v2Especial2p29

Brittos e Dourado (2013) contribuem com os esforços em discutir as relações comunicacionais apresentando que o espaço de discussão da EPC une pesquisadores e universidades em diversas perspectivas comprometidas com campo de estudos, que possui "um olhar crítico ao dinâmico cenário econômico político - tecnológico do capitalismo global" (BRITTOS; DOURADO, 2013, p.40).

Tendo por base as contribuições teóricas da EPC, Andrade (2013) afirma em pesquisa as consequências trazidas ao jornalismo e à comunicação dadas às referências de capitalismo avançado levantadas pela pesquisadora. A autora aponta que mudanças nas práticas jornalísticas são ocasionadas pela reconfiguração capitalista, onde o jornalismo passa por transformações no ambiente ditado pelas indústrias culturais, um espaço sem regulamentações e que atende a lógica econômica centrada na lucratividade; além disso, que o jornalismo noticioso em obediência aos ditames do capitalismo avançado se afasta do conceito de prestação de serviço e se torna mais pragmático e menos crítico, também é caracterizado um modelo de jornalismo informativo das indústrias culturais. A autora sugere uma lista do que chamou de mutações do jornalismo:

Observar esses fenômenos como mutações é flagrante de sua condição histórica, que se esconde atrás de uma força hegemônica sustentada por grandes empresas de comunicação, com interesses no capitalismo geral, e também reproduzida em empresas menores que seguem os formatos hegemônicos sem grandes questionamentos, tanto de produção de conteúdo como de modelos administrativos. (ANDRADE, 2013, p.122-123).

É importante enfatizar que as reflexões na área visam problematizar as relações existentes na sociedade que vive em meio aos ditames dos oligopólios comunicacionais, mas diante dos entraves apontados pela grande mídia surgem alternativas para que os telespectadores possam acompanhar outros conteúdos. Mas, do ponto de vista teórico, qual a reflexão sobre a Comunicação Pública? 


\title{
Obsevisto
}

ISSN n² $2447-4266$

Vol. 2, Especial 2, outubro. 2016

DOI: http://dx.doi.org/10.20873/uft.2447-4266.2016v2Especial2p29

\section{Comunicação Pública e Cidadania}

A mídia é tida para a sociedade como um espaço de entretenimento, mas para alguns segmentos como de reivindicação e luta, sendo também um campo para a busca pela cidadania. No caso do jornalismo televisivo é ampliada a participação popular. Conforme Coutinho (2012) houve uma maior utilização do povo fala, onde o cidadão comum tem maior destaque e tempo nas falas editadas nos telejornais, a pesquisadora acrescenta ainda que é possível notar que em termos quantitativos a qualitativos. Ao refletir sobre a prática do telejornalismo a pesquisadora Ana Carolina Temer, apresenta que:

\begin{abstract}
Embora não contemple toda a complexidade filosófica- epistemológica da atividade profissional do telejornalismo esta definição deixa claro que o jornalismo se caracteriza por ser uma atividade social que busca entender, a partir dos limites éticos predefinidos, parte da essência do que é ser humano: a curiosidade do ser humano de saber sobre os outros homens. $\mathrm{O}$ jornalismo é um elemento de articulação entre o indivíduo e o coletivo, o homem e suas necessidades para sobrevivência, a ação humana e seu significado social, e que realiza essa articulação fornecendo informações. (TEMER, 2010, p. 102-103).
\end{abstract}

Apesar disso, os espaços que deveriam ser ocupados por uma lógica mais cidadã, ainda são ocupados pela lucratividade. Diante disso, Brittos e Bolaño (2006, p.12) mencionam o espaço público é o espaço social, o que, na sua versão midiática contemporânea, mais do que nunca é regido por decisões privadas, mesmo quando midiatiza temas públicos de forma pretensamente pluralista.

Moraes (2001) aborda que as corporações da mídia na contemporaneidade funcionam como agentes discursivos e ideológicos a partir da ordem global, onde "os conglomerados de mídia atuam como agentes econômicos globais, contribuindo para revigorar o modo de produção capitalista" (MORAES, 2001, p.1), 


\title{
Observistotório
}

DOI: http://dx.doi.org/10.20873/uft.2447-4266.2016v2Especial2p29

sob a égide da retórica de uma globalização que mede a expressão cultural pelo consumo de indivíduos e grupos.

Segundo Mattos (2002) outro ponto importante para ampliar a discussão sobre a temática está apresentado na Constituição Brasileira, também chamada de Constituição Cidadã deve ser visto com bastante enfoque pelos diversos segmentos sociais:

\begin{abstract}
A carta de 1988 também fixou normas para a produção de uma programação das emissoras de rádio e televisão. De acordo com o artigo 221 , as emissoras devem promover programas com finalidades educativas, artísticas, culturais e informativas, procurando estimular a produção independente, visando a promoção da cultura nacional e regional (MATTOS, 2002, p.118).
\end{abstract}

A discussão sobre o que está posto no documento que rege nosso país é de fundamental importância para que sejam cobradas iniciativas para o cumprimento do que está posto na Carta Magna, oferecendo assim garantias de acesso à informação por parte da população de todos os recantos do Brasil.

Outra autora que reforça a importância de estratégias de democratização do acesso de vários segmentos sociais é Cecília Perruzzo, a estudiosa expõe a importância desse tipo de veículo, onde:

O meio de comunicação local tem a possibilidade de mostrar melhor do que qualquer outro a vida em determinadas regiões, municípios, cidades, vilas, bairros, zonas rurais etc. Por vezes, se cerca de distorções, como as que tem origem em vínculos com interesse político-partidários e econômicos, mas, mesmo acarretando vieses de informação, acaba contribuindo na divulgação de temas locais (PERUZZO, 2005, p. 7).

Em 2005, no Seminário Mídia Cidadã, pesquisadores da comunicação e ativistas midiáticos, participantes de movimentos sociais discutiram vários pontos e elaboraram, segundo Marques de Melo (2006), um documento intitulado Carta de São Bernardo, que trouxe algumas questões; entre elas o papel da mídia local/ regional para o desenvolvimento da cidadania, questões sociais, bem como 


\section{Observatório}

ISSN n² 2447-4266

Vol. 2, Especial 2, outubro. 2016

DOI: http://dx.doi.org/10.20873/uft.2447-4266.2016v2Especial2p29

posturas econômicas, políticas e culturais, que buscaram contribuir para uma mídia cidadã mais focada em atender os interesses coletivos.

A globalização dita ricos e pobres, no entanto, autores buscam uma reflexão diferenciada em prol da melhoria da qualidade de vida da população a partir de um processo diferenciado. Santos (2010) diz que:

Ser cidadão de um país, sobretudo quando o território é extenso e desigual, pode constituir, apenas uma perspectiva de cidadania integral, a ser alcançada em escalas sub-nacionais, a começar pelo nível local. Esse é o caso brasileiro, em que a realização da cidadania, reclama, nas condições atuais uma revalorização dos lugares e uma adequação de seu estatuto político (SANTOS, 2010, p.113).

O geógrafo acrescenta ainda que a busca por uma cidadania plena deve ser dada a partir de soluções locais buscadas pelas pessoas, somada a uma nova estruturação político- territorial que passa também por uma redistribuição de recursos, prerrogativas e obrigações.

Ao refletir sobre o capital da mídia na lógica da globalização, Dênis de Moraes (2001), elenca pontos que auxiliam na articulação do perfil do cenário midiático global. Primeiramente, a mudança no paradigma comunicacional, onde a mudança ocorre por meio da digitalização. Como segundo aspecto, está o modelo organizacional das corporações de mídia que em virtude da abertura dos mercados permite a instalação de grupos com sede nos Estados Unidos da América. Por último, cita os arranjos, onde empresas de menor porte precisam se unir às líderes para defender a manutenção no mercado.

A alternativa apresentada, ainda no trabalho de Moraes, para preservar a liberdade do fluxo de informações e conteúdos culturais está na revitalização da sociedade civil, assim como a articulação de forças comunitárias para que sejam traçadas iniciativas concretas para conter a mercantilização generalizada. Para isso, afirma que são necessárias políticas comunicacionais com princípios democráticos de regulação, concessão, tributação e fiscalização. Esforços para garantir políticas 


\section{Observatório}

DOI: http://dx.doi.org/10.20873/uft.2447-4266.2016v2Especial2p29

comunicacionais mais amplas que possam ir além da lógica regional e local. "Torna-se crucial conceber alianças e coalizões de forças de todos os quadrantes, como meio de tentar frear, em um duradouro e persistente processo de lutas, a neurose por lucro a qualquer preço" (MORAES, 2001, p.1).

Diante do panorama apresentado, é preciso refletir sobre o que é a Comunicação Pública, partindo primeiramente do conceito de tal terminologia. Duarte (2001) reforça o quanto "costumeiramente esta relacionado à difusão de ideias, mas também tratado como sistema público de radiodifusão" (DUARTE, 2001, p. 122). É importante estabelecer que a Comunicação Pública deve ter as informações temáticas de interesse coletivo voltadas a uma perspectiva cidadã. Também que incluem:

Tudo que está relacionado ao aparato estatal, às ações governamentais, a partidos políticos, ao legislativo, ao judiciário, ao terceiro setor, às instituições representativas, ao cidadão individualmente e, em certas circunstâncias ações privadas. (DUARTE, 2001, p. 1226).

Em uma análise sobre a TV Pública na América Latina, Becerra (2013) cita que tanto em meios comerciais quanto em governamentais existem modelos extremos. Um deles é o utilitário que busca justificar as estratégias de negócio. Já outro, propagandista, que está fundamentado na utilização de meios estatais para a promoção de informações parciais. Para o autor, nos dois casos, a sociedade está convertida a uma posição clientelar, onde cidadãs e cidadãos são vistos como clientes, ora comerciais ora políticos.

Valente (2009) traça a discussão das emissoras de TV com caráter público no Brasil, o pesquisador traz a seguinte definição sobre a televisão pública:

Como um aparelho de Estado que desempenha uma função de reprodução ideológica, por meio do estabelecimento de 'consensos' construídos a partir do embate entre forças que disputam o seu controle e entre estas e as demandas do publico a que se dirige, devendo, para isso, atuar na Indústria Cultural em concorrência com outros agentes a partir da tensão entre seu modelo de 


\section{Observatório}

ISSN n² 2447-4266

Vol. 2, Especial 2, outubro. 2016

DOI: http://dx.doi.org/10.20873/uft.2447-4266.2016v2Especial2p29

financiamento disfuncional ao espaço e a resistência dos capitais à sua presença (VALENTE, 2009, p.51).

Já Miguel e Macamo (2013) veem uma possibilidade de modificar a estrutura vigente apresentada. Para isso, deve haver uma mudança na forma como os meios de comunicação trabalham, deixando a forma industrial e tornando-se um serviço público, tendo a obrigação de prestar contas à sociedade das atitudes tomadas.

Em se tratando de possibilidades de alterar o atual sistema, há um conjunto de esforços refletindo a lógica atual do processo de difusão da informação, em um dos discursos trazidos por teóricos:

Os meios de comunicação são elementos de orientação social. Desse modo, é premente a transparência na divulgação de informações. Para isso, faz-se necessária a independência da mídia em relação às lógicas econômicas e aos organismos governamentais. O fortalecimento da sociedade civil organizada, com o propósito de propor pautas alternativas e a criação de uma legislação que contemple elementos de interesse social e supra as lacunas existentes no setor, o expoente da EPC, a reflexão pela formação de uma cidadania autônoma nas democracias modernas (BRITTOS; DOURADO, 2013, p.50).

Diante da exposição sobre uma lógica conceitual faz necessário pontuar aspectos sobre os conteúdos do telejornalismo público, partindo primeiro das notícias, conteúdos essenciais na lógica comunicacional. Para isso, faz-se necessário pensar a atualidade no contexto jornalístico, que é uma preocupação ressaltada na tese de Carlos Franciscato (2003), no trabalho o autor expõe o quando esse aspecto de interação social deve "construir sociabilidade que podem conduzir a produção de ações públicas - não somente ações racionais e resultantes de um debate com informações trazidas pelo jornalismo ou mesmo conduzido por este" (FRANCISCATO, 2003, p.301), mas que possa trazer nos conteúdos exibidos as tragédias e mazelas da humanidade.

Ao enfatizar as instâncias comunicativas é preciso situar os conteúdos veiculados nas TVs Públicas, conforme apresenta Fuenzalida (2015), que nesses 


\section{Observatório}

ISSN n²447-4266

Vol. 2, Especial 2, outubro. 2016

DOI: http://dx.doi.org/10.20873/uft.2447-4266.2016v2Especial2p29

espaços podem ser expostos novos temas em pauta, a citar os noticiários ou debates, no último surge o que o autor denomina como "Nova Função do Jornalista", onde o profissional precisa exercer uma "função comunicacional de articulador do trio chave de políticos, especialistas/ acadêmicos e as organizações cidadãs quanto aos problemas e demandas" (FUENZALIDA, 2015, p. 116).

O papel de vigilância do poder público também é um ponto que merece destaque, visto que o cidadão deve cumprir também o papel fiscalizador que vai além do papel desempenhado como eleitor, conforme reflexão de Pérsigo e Fossá (2015), onde "a prática da comunicação demanda assumir um comprometimento com interesse coletivo, preterindo benefícios individuais, ou corporativos" (PÉRSIGO E FOSSÁ, 2015, p. 237).

Segundo Dib, Aguiar e Barreto (2010), a chave para melhorar a formação dos profissionais está apresentada na Economia Política das Cartografias Profissionais, sendo que a formação do jornalista não deve estar somente direcionada à carreira, mas também inserida em questões voltadas às políticas de comunicação. Ainda, de acordo com os autores, as informações jornalísticas estão configuradas como espaço de luta, onde diversas forças (sociais, políticas e econômicas) disputam tanto pela construção discursiva quando pela produção de sentidos que ocorre sobre a realidade social.

Partindo da reflexão dos pesquisadores, o quanto uma mídia que ofereça espaços para a participação social pode se configurar como um espaço cidadão no campo midiático. Essa possibilidade está apresentada em emissoras públicas, desde que cumpram o papel de propiciar uma verdadeira formação cidadã àqueles que acompanham a programação, com conteúdos produzidos com essa finalidade.

\section{Considerações Finais}

O conhecimento se faz pela reflexão e compromisso de compreender as relações dadas por meio das discussões teóricas travadas ao longo da história. No 


\section{Obevisto \\ ISSN n²447-4266 \\ Vol. 2, Especial 2, outubro. 2016 \\ DOI: http://dx.doi.org/10.20873/uft.2447-4266.2016v2Especial2p29}

caso das teorias da comunicação, faz-se necessária uma missão ampla de compreensão dos conceitos tratados nas discussões cotidianas que aliam teoria e prática, no caso do campo comunicacional.

Para isso, foi traçado um percurso tendo por base as contribuições de estudiosos que refletiram sobre as relações da Economia Política da Comunicação, desde o nascedouro das reflexões sobre as relações mercadológicas na difusão da arte e que percorreram os espaços comunicacionais, tarefa abordada pelas indústrias culturais.

Também, uma reflexão sobre os veículos de Comunicação Pública, que se configuram como espaços importantes, em meio ao cenário comunicacional vigente atrelado aos ditames de mercados centrados nas mãos de grandes corporações. Ao citar o caso do Mercado Brasileiro de Televisão, assim como outras mídias que estão concentradas nas mãos de grupos familiares, sendo a TV considerada o principal mecanismo das indústrias culturais no cenário atual.

O jornalista tem um papel decisivo ao repassar as informações, mas em veículos de Comunicação Pública com a missão de propagar conteúdos cidadãos, o trabalho deve ter alicerce em bases sólidas de participação da sociedade civil, confiando aos atores sociais um papel importante, muitas vezes relegado a interesses econômicos e políticos pela grande imprensa.

\section{Referências}

ANDRADE, Samária Araújo de. Jornalismo em Mutação: estudo sobre a produção de conteúdo na fase do capitalismo avançado. Dissertação (mestrado)- Universidade Federal do Piauí, Programa de Pós Graduação em Comunicação, 2013. Orientação: Prof. Dra. Jacqueline Lima Dourado. Disponível em < http://www.sigaa.ufpi.br/sigaa/verProducao?idProducao=211550\&key=170da1b02cfd2aa3b 6b889f4c98cc56d> Acesso em 10/ 05/2015. 


\section{Obevisto \\ ISSN n²447-4266 \\ Vol. 2, Especial 2, outubro. 2016 \\ DOI: http://dx.doi.org/10.20873/uft.2447-4266.2016v2Especial2p29}

BRITTOS, Valério Cruz; BOLAÑO, César R. S. TV pública, políticas de comunicação e democratização: movimentos conjunturais e mudança estrutural. Revista de Economía Política de las Tecnologías de la Información y Comunicación www.eptic.com.br, vol. X, n.3, Sep. - Dic. / 2008.

BECERRA, Martín. La televisión pública em América Latina: condicionantes y desafios. P.179205. In: DOURADO, Jacqueline Lima. Economia Política do Jornalismo: campo, objeto, convergências e regionalismo. EDUFPI. Teresina. 2013.

BRITTOS, Valério \& DOURADO, Jacqueline Lima. P. 39- 51. Avanços brasileiros da Economia Política da Comunicação: 25 anos de estudos, pesquisas e debates. In: MARQUES DE MELO, José \& MELO, Patrícia Bandeira de (org.). Economia Política da comunicação: vanguardismo nordestino/ Recife: Fundação Joaquim Nabuco, Editora Massangana, 2013.216p.

CHRISTOFOLETTI, Rogério. Dez impasses para uma efetiva crítica de mídia no Brasil. IN: Anais do $26^{\circ}$ Congresso Brasileiro de Ciências da Comunicação. Intercom, Belo Horizonte, 2003.

Disponível em http://www.portcom.intercom.org.br/pdfs/83181657908623038781927642374779165362.pd f> Acesso em 18/05/2015.

COUTINHO, Iluska. Telejornalismo e público - Sobre vínculos com o cidadão, convertido em audiência. P. 21-42. In: O Brasil (é)ditado. Flávio Porcello, Alfredo Vizeu e Iluska Coutinho. (Orgs.). Coleção Jornalismo Audiovisual. V.1. Florianópolis: Insular, 2012.

DIB, Sandra. Korman.; AGUIAR, Leonel. Azevedo. de; BARRETO, Ivana. Economia Política das cartografias profissionais: a formação específica para o jornalismo. In: XIX ENCONTRO ANUAL DA COMPÓS. Rio de Janeiro: PUC-Rio, 2010. Disponível em < http://compos.com.puc- 


\section{Obevisto \\ ISSN n² 2447-4266 \\ Vol. 2, Especial 2, outubro. 2016 \\ DOI: http://dx.doi.org/10.20873/uft.2447-4266.2016v2Especial2p29}

rio.br/media/g6_sandra_korman_dib_leonel_azevedo_aguiar_ivana_barreto.pdf $>$. Acesso em 20/06/2015.

DOURADO, Jacqueline Lima \& ANDRADE, Samária Araújo. Caminhos cruzados do jornalismo e mercado: a produção de conteúdo no Jornal do Piaú. In: : DOURADO, Jacqueline Lima. Economia Política do Jornalismo: campo, objeto, convergências e regionalismo. EDUFPI. Teresina. 2013.

DUARTE, Jorge. Sob a emergência do (s) conceito (s) de comunicação pública. In: Comunicação pública, sociedade e cidadania. $1^{a}$ ed. São Caetano do Sul, SP: Difusão Editora, 2011. (Série Pensamento e Prática; v.4)

FRANCISCATO, Carlos Eduardo. A atualidade do jornalismo bases para sua delimitação teórica. Tese (Doutorado)- Universidade Federal da Bahia, Programa de Pós- Graduação em Comunicação e Cultura Contemporânea, 2003. Orientação. Prof. Dr. Antônio Albino Canelas Rubim.

FILHO, Adilson Vaz Cabral.. As bestas do Apocalipse: a teoria adorniana da indústria cultural. In: Teorias da Comunicação: Correntes de Pensamento e Metodologia de Ensino [recurso eletrônico]/ Organizadores Rose Maria Vidal de Souza, José Marques de Melo, Osvando J. de Moraes. São Paulo, INTERCOM, 2014. Disponível em < http://www.portcom.intercom.org.br/ebooks/arquivos/8ba840f439e5d6b8c5eb6ce94faeca68 .pdf> . Acesso em: 10/06/2015

FUENZALIDA, Valerio. Televisão pública e mudança digital: tecnologia TV - audiências formatos. MATRIZes. Vol.9. n.1, 2015. P. 103- 126, 2015. DOI: http://dx.doi.org/10.11606/issn.1982-8160.v9i1p103-126

MATTOS, Sérgio. História da televisão brasileira. 2. ed. Petrópolis: Vozes, 2002. 


\section{Obevisto \\ ISSN n²447-4266 \\ Vol. 2, Especial 2, outubro. 2016 \\ DOI: http://dx.doi.org/10.20873/uft.2447-4266.2016v2Especial2p29}

MARQUES DE MELO, José. Mídia e Cidadania no Brasil. p. 21-33. In: MARQUES DE MELO, José; GOBBI, Maria Cristina \& SATHLER, Luciano. Mídia Cidadã: utopia brasileira. São Bernardo do Campo: Universidade Metodista de São Paulo, 2006.

MARQUES DE MELO, José \& MELO, Patrícia Bandeira de (org). Economia política da comunicação: vanguardismo nordestino. Recife: Fundação Joaquim Nabuco, Editora Massangana, 2013.

MELO, Patrícia Bandeira de. Barbosa Lima Sobrinho, precursor dos estudos brasileiros sobre a economia da imprensa. P. 73-90. In: MELO, José Marques de \& MELO, Patrícia Bandeira de (org.). Economia Política da comunicação: vanguardismo nordestino/ Recife: Fundação Joaquim Nabuco, Editora Massangana, 2013. 216p.

MIGUEL, João \& MACAMO, Inácio Júlio. Economia política do jornalismo televisivo moçambicano P-110-126 In: DOURADO, Jacqueline Lima. Economia Política do Jornalismo: campo, objeto, convergências e regionalismo. UFPI. Teresina. 2013.

MOSCO, Vincent. Economia Política da comunicação: uma perspectiva laboral. P. 97-120. Comunicação e Sociedade, cadernos do Noroeste, Série Comunicação, vol 12 (1-2), 1999.

MORAES, Dênis de. $\mathbf{O}$ capital da mídia na lógica da globalização Ciberlegenda. Revista do Programa de Pós- Graduação em Comunicação da Unversidade Federal Fluminense, n.06,p.1-8, 2001. Disponível em: < http://www.uff.br/ciberlegenda/ojs/index.php/revista/article/view/316/197 >. Acesso em $10 / 07 / 2015$.

PÉRSIGO, Patrícia Milano \& FOSSÁ, Maria Ivete Trevisan. A midiatização da comunicação pública: um olhar sobre a discutibilidade dos escândalos políticos. MATRIZes. Vol.9. n.1, 2015. P. 229-241, 2015. DOI: http://dx.doi.org/10.11606/issn.1982-8160.v9i1p229-241 


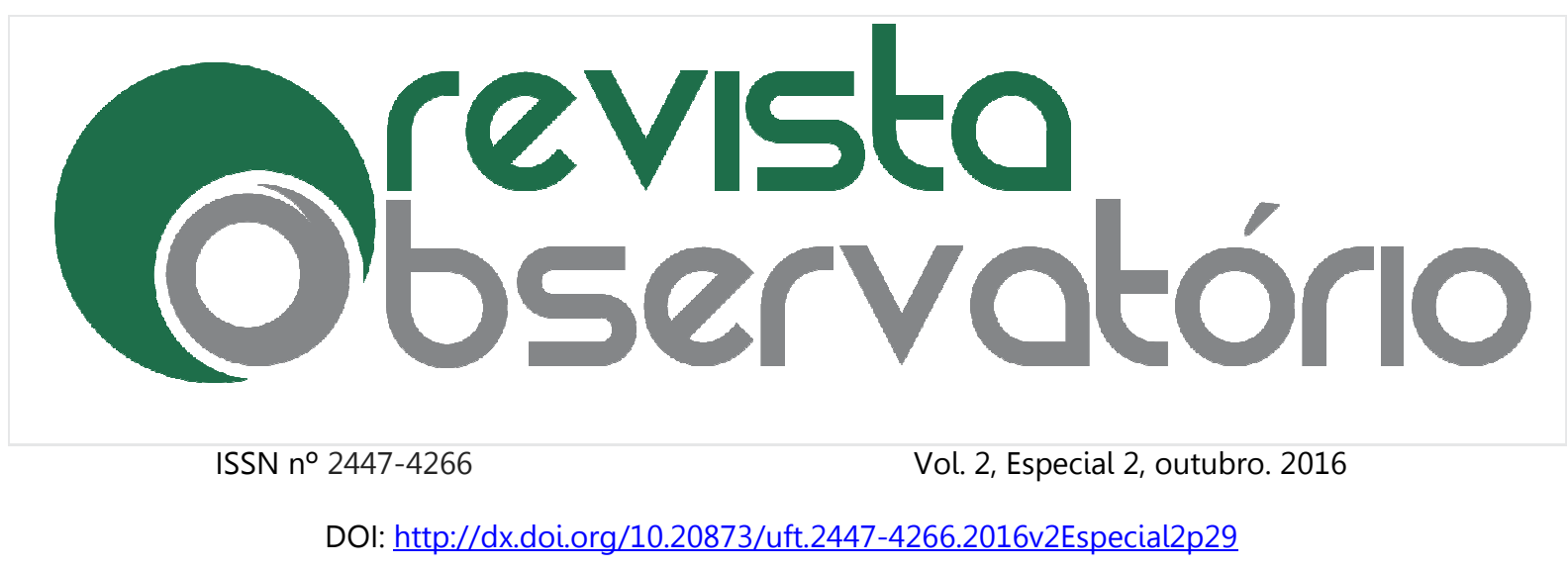

PERUZZO, Cicília M. Krohling. Mídia regional e local: aspectos conceituais e tendência. In: Revista Comunicação \& Sociedade. São Bernardo do Campo: Póscom-Umesp, a. 26, n. 43, p. 67-84, 2005.

SANTOS, Milton. Por uma outra globalização: do pensamento único a consciência universal. 19ª Ed; Rio de Janeiro: Record, 2010.

TEMER, Ana Carolina Rocha Pessoa. A mistura dos gêneros e o futuro do telejornal. In: 60 anos de telejornalismo no Brasil: história, análise e crítica/ Alfredo Vizeu, Flavio Porcello, Iluska Coutinho (orgs.).Florianopólis: Insular, 2010.

VALENTE, Jonas. TV Pública no Brasil e sua inserção no modo de regulação setorial da televisão brasileira. Dissertação (mestrado)—Universidade de Brasília, Programa de PósGraduação em Comunicação, 9 de julho de 2009. Orientação: Prof. Dr. César R.S. Bolaño.

VIZEU, Alfredo. Decidindo o que é notícia: os bastidores do telejornalismo. 4. ed. Porto Alegre: EDIPUCRS, 2005. 